\title{
Pharmacological and non-pharmacological treatment approaches to chronic lumbar back pain
}

\author{
Ayşegül Ketenci@, Mert Zure@ \\ Department of Physical Medicine and Rehabilitation, Istanbul University Istanbul Faculty of Medicine, Istanbul, Turkey
}

Received: January 16, 2021 Accepted: February 01, 2021 Published online: March 04, 2021

\begin{abstract}
Low back pain is a common and important cause of disability. Chronic pain increases disability and cost. In this review, we discuss pharmacological and non-pharmacological treatment approaches for chronic low back pain in the light of current data and guidelines.

Keywords: Chronic pain, drugs, exercise, low back pain, physical therapy, transcutaneous electric nerve stimulation.
\end{abstract}

Low back pain is a common symptom, seen at all ages, from children to the elderly. It is a symptom to be seen frequently in high, middle, and low-income countries. Years lived with disability due to low back pain increased by $54 \%$ globally between 1990 and 2015, particularly due to the population growth and aging. To elaborate, the largest portion of this increase was seen in low-income and middleincome countries. Low back pain is currently the leading cause of disability worldwide, despite the huge health resources and intense efforts allocated to this area all over the world. ${ }^{[1,2]}$

A specific pathology causing low back pain can be rarely identified; therefore, most of the back pain is referred to as non-specific low back pain. In case of persistence for more than 12 weeks, it is referred to as chronic low back pain (CLBP) ${ }^{[1,3]}$ It is a condition that disrupts functionality, social participation, mental and financial well-being and needs to be examined in biophysical, psychological, and social dimensions. ${ }^{[1]}$

Many current clinical practice guidelines recommend similar approaches for the assessment and treatment of CLBP. While a few guidelines contain recommendations for more specific pathologies such as spinal stenosis and lumbar disc herniation, due to the often coexistence of these situations and the difficulties in specifying the cause of lumbar back pain, the most common and appropriate approach to CLBP is to evaluate the patient in general, rather than to define the primary affecting factor. ${ }^{[4,5]}$

There are many treatment options in the treatment of CLBP that have not been shown to be superior to each other. The choice between these options should be based on the preference of the physician and patient, while these treatment options are mostly encouraged to be used in combination. However, the continuation of the activity and active participation of the patient in the treatment constitute the first steps of all current treatment recommendations. ${ }^{[6]}$ At the time of writing this article, the most up-to-date diagnosis, evaluation, and treatment guide is the 2020 guide created by the North American Spine Society (NASS) with the collaboration of researchers from different branches working in this field. ${ }^{[7]}$

According to the current guidelines, bed rest in the early stage has been abandoned in the treatment

Corresponding author: Ayşegül Ketenci, MD. İstanbul Üniversitesi İstanbul Tıp Fakültesi, Fiziksel Tıp ve Rehabilitasyon Anabilim Dal, 34093 Fatih, İstanbul, Türkiye. e-mail: draysegulketenci@hotmail.com 
of both CLBP and acute low back pain. Regardless of the duration of the symptom, patients should be reassured that back pain is a controllable condition and symptoms would subside over time, encouraged to stay active and continue daily activities, including work. Therefore, patient education, which would ensure the patients' understanding of the natural course of symptoms and their own responsibility in pain management, is a must for the treatment. It is recommended that psychological treatment packages such as cognitive behavioral therapy (CBT), progressive relaxation, and mindfulness-based stress reduction should be evaluated for individuals who do not respond to these treatments and have persistent low back or radicular pain. ${ }^{[2,3]}$

Using media, an important way to reach the people currently, to change the false beliefs in both patients and healthcare providers about low back pain such as "staying still and resting is a must" is shown to be an effective strategy in studies with long-term follow-ups conducted in different countries. However, changing belief into behavior is a more complex process. $^{[8]}$

\section{PHARMACOLOGICAL TREATMENT}

Pharmacological treatment is recommended for use in cases of inadequate response to first-line therapy. ${ }^{[2,3]}$

\section{Acetaminophen}

Acetaminophen, a very well-known analgesic drug with an uncertain mechanism of action, is frequently used as the first-line drug by patients with CLBP. The frequent use of acetaminophen is owing to the easy access to the drug and its relatively favorable risk profile, although current evidence shows acetaminophen is not more effective than placebo in controlling CLBP. ${ }^{[9,10]}$ Therefore, it is not recommended to be used in the treatment. ${ }^{[2,3]}$

\section{Non-steroidal Anti-inflammatory Drugs (NSAIDs)}

The NSAIDs provide some improvement in functionality and short-term relief in non-radiculopathy-related CLBP (Table 1), also no difference has been shown in the efficacy profile between different NSAIDs. ${ }^{[3,10,11]}$ However, in a Cochrane review mostly consisting of studies with low-quality evidence, no significant difference was found between NSAIDs and placebo in controlling radicular symptoms. ${ }^{[12]}$ Many guidelines recommend the use of NSAIDs for patients with CLBP, taking into account the risk of adverse events (i.e., renal, cardiovascular and gastrointestinal). ${ }^{[3,9,10]}$ It is recommended that NSAIDs should be used at the lowest effective dose for the shortest possible duration, and concomitant gastroprotective therapy should be used with NSAIDs. ${ }^{[1]}$ There is an insufficient number of data on the use of cyclooxygenase-2 selective NSAIDs in low back pain. ${ }^{[7]}$

\section{Myorelaxant drugs}

Myorelaxants are usually prescribed, when low back pain is thought to be of myofascial origin, and its combination with acetaminophen and NSAIDs are frequently used in clinical practice. ${ }^{[1]}$ In a systematic review on the efficacy of myorelaxants (except for benzodiazepines) in CLBP, only short-term analgesic benefit was reported. ${ }^{[13]}$ The evidence for benzodiazepine use in CLBP treatment is also limited, and benzodiazepines have been found to be more effective in acute low back pain than in chronic pain. As myorelaxant drugs cause drowsiness, they also have the potential to create addiction in the patient. In summary, there is no supportive evidence that long-term use of myorelaxants would be beneficial in CLBP treatment, these drugs are recommended to be used for short periods in patients with severe, frequent muscle spasms accompanying CLBP. ${ }^{[2,3,11]}$

\section{Antiepileptic drugs}

Gabapentin and pregabalin are used as firstline therapy in the treatment of neuropathic pain, and are frequently prescribed in daily practice, as neuropathic mechanisms play a critical role in the emergence of lumbosacral radicular pain and neurogenic claudication. ${ }^{[1]}$ Systematic reviews on the role of gabapentinoids in the treatment of CLBP with or without radicular pain ${ }^{[14,15]}$ reported no significant benefit in favor of gabapentinoids, compared to placebo or other analgesics. Moreover, there are concerns about the side effects of gabapentinoids such as confusion, dizziness, fatigue and visual disturbances and addiction that occurs with the long-term use of these drugs. According to recent guidelines, these drugs can only play a role in treatment of CLBP in the presence of a strong neuropathic pain component. In this case, it would be reasonable to have a medication trial period of up to four weeks at therapeutic doses and, if no benefit is seen, gradual cessation of treatment is recommended. ${ }^{[1]}$

\section{Antidepressant drugs}

Antidepressant drugs other than duloxetine have not been shown to be superior to placebo as an analgesic in CLBP and are recommended to be added to the treatment only in the presence of concomitant 


\begin{tabular}{|lc|}
\multicolumn{1}{|c|}{ TABLE 1 } \\
\multicolumn{1}{|c|}{ Pharmacological treatment for chronic low back pain ${ }^{[7]}$} & Grade of recommendation \\
\hline $\begin{array}{l}\text { NSAIDs (non-selective): Suggested for the treatment of CLBP } \\
\text { Opioids: Should be used cautiously with short duration }\end{array}$ & B \\
$\begin{array}{l}\text { Topical capsicum: Recommended as an effective treatment for low back pain on a short term basis } \\
\text { (3 months or less). }\end{array}$ & B \\
Selective NSAIDs: Insufficient evidence to make a recommendation for or against & I \\
Anticonvulsants: Insufficient evidence to make a recommendation for or against & I \\
Lidocaine patch: Insufficient evidence to make a recommendation for or against & I \\
Antidepressants: Not recommended for the treatment of low back pain & A \\
Oral or intravenous steroids: Not effective for the treatment of CLBP & B \\
\hline NSAIDs: Non-steroidal anti-inflammatory drugs; CLBP: Chronic low back pain & \\
\hline
\end{tabular}

depression. ${ }^{[16]}$ Yet, duloxetine is shown to be superior to placebo in pain control and improvement of functionality in CLBP. Therefore, particularly in CLBP patients with neuropathic pain components, duloxetine can be used at therapeutic doses for up to four weeks and ceased, if no benefit is seen. ${ }^{[10,17]}$ Still, duloxetine has not been included in the current guidelines due to dose differences, small sample sizes, short follow-up periods, and limited effect in conducted studies. ${ }^{[17]}$

\section{Opioids}

Opioids are one of the most commonly prescribed drugs in CLBP. It is shown to be effective in terms of pain relief and improving functionality in short-term use, but long-term effectiveness and safety of use are uncertain. Routine use of opioids is not recommended, as their advantages are small and there are significant risks such as overdose and addictive potential. The guidelines note that opioids should only be used in selected patients, for a short period and with appropriate monitoring (Table 1). ${ }^{[2,3,11]}$

\section{Other drugs}

The use of systemic corticosteroids in CLBP has not been found to be effective in pain control. Therefore, the use of oral or intravenous (IV) corticosteroids is not recommended. ${ }^{[7]}$ Although data on the use of topical lidocaine are unclear, the use of topical capsaicin for a period of less than three months is recommended (Table 1)..$^{7718]}$ In a study investigating the effects of magnesium, an N-methyl-D-aspartate (NMDA) antagonist, the addition of IV and, then, oral magnesium to conventional treatment provided pain control up to six months in CLBP patients with a neuropathic component. The need for comprehensive studies on this subject was emphasized in this study. ${ }^{[19]}$

Choosing the appropriate pharmacotherapy for low back pain remain to be a major challenge for clinicians. Identifying different phenotypes that respond to targeted therapies, improving the diagnostic phase to create mechanism-oriented therapy rather than symptom-based treatment of pain and treating symptoms that interfere with other elements of therapy, such as concomitant depression and sleep disorder, are promising approaches. The low number of effective pharmacological treatments in CLBP has led researchers to many further studies searching for more effective and safer drugs. Antibiotic therapy, cannabinoids, novel opioids, calcitonin, melatonin, nerve growth factor inhibitors, ketamine and botulinum toxin have been evaluated in several clinical trials for CLBP. Evidence on the effectiveness of some of these treatments is conflicting and some are still limited. In a review published in 2020, the efficacy of amoxicillin treatment for Modic changes could not be detected. ${ }^{[11,20-22]}$

\section{NON-PHARMACOLOGICAL TREATMENT}

Before evaluating non-pharmacological treatments, it would be useful to highlight the barriers that clinicians face in studying the effectiveness of these treatments. Unlike injections or medications, many treatments in this topic involve physical actions (physical contact, exercise, speech) that are difficult to imitate with a placebo form. This leads to a limitation in studying the effects of non-pharmacological treatments, as many other factors may be responsible for treatment outcomes such as clinician-patient 
interaction, environmental stress, trust between the parties and patient expectations. This refers that a treatment that is, indeed largely ineffective, but administered by a confident clinician with a good interaction might produce good results or vice versa; a largely successful treatment method in a non-ideal environment can lead to unsuccessful results in a particular case. In brief, scientific difficulties should definitely be taken into consideration while evaluating non-pharmacological treatments such as exercise, physical therapy methods, psychosocial therapies, and complementary medicine methods. ${ }^{[23]}$

In 2020, the guidelines for non-specific low back pain and neck pain published and applied in European countries after 2013 were compiled in a review. The emphasis in this compilation review is that non-pharmacological treatments such as patient education, remaining active and exercise programs/therapy are recommended for all back pain patients, whereas psychological therapies and multidisciplinary treatment are recommended only for specific groups. ${ }^{[24]}$

\section{EXERCISE THERAPY}

All guidelines recommend including a gradual activity and exercise program in the treatment, particularly in patients with CLBP $(>12$ weeks duration), with the aim of improving functionality and preventing disability. Exercise programs have been shown to reduce kinesiophobia (moderate-quality evidence) and fear-avoidance beliefs (low-quality evidence). Since there is no solid evidence to suggest that one form of exercise is better than another, guidelines recommend considering individual needs, preferences and abilities while deciding on exercise type. Supervised exercise therapy is often unnecessary in the early stages; it may only be considered in patients with no or slow improvement or risk factors for pain that would likely cause permanent disability. ${ }^{[2,23,25]}$

However, among the recommendations of the guidelines, there are many differences on when to start exercise (in the presence of acute back pain or after chronicity), which type of exercise program to select (stabilization exercises, stretching exercises, Feldenkrais, pilates, yoga, water exercises, McKenzie exercise approach, Tai-Chi) and the structure of program (individual home programs, supervised exercise, group exercises). ${ }^{[3,26,27]}$ A pilot study published in 2020 reported that three days a week of an exercise program providing a total of $30.8 \mathrm{kcal} / \mathrm{kg}$ energy expenditure per week is a suitable level of exercise for pain control of patients with CLBP. ${ }^{[28]}$ For stabilization exercise programs in low back pain patients, training frequency should be three to five times per week, while training duration should be 20 to 30 min per session to cause the largest impact on the effect sizes (both in pain and disability). ${ }^{[29]}$

The most commonly used exercise programs are those targeting the motor control of the abdominal muscles that provide stabilization. Lumbar spinal stability loss is considered a risk factor for developing low back pain. The transversus abdominis, which is the deepest abdominal muscle, plays a major role in stabilizing the lumbopelvic region. Thus, decreased activation of this muscle is thought to be associated with the occurrence and progression of low back pain. ${ }^{[30]}$ Therefore, it is recommended to increase the activation and to strengthen the transversus abdominis muscle not only in the treatment program but also afterwards, to prevent recurrence of symptoms. It has been shown that the highest transversus abdominis activation occurs with abdominal self-bracing in the bridge position, and it is recommended that this exercise be added to the treatment in patients with suspected stabilization deficiency. ${ }^{[30]}$

The whole-body vibration technique is also frequently used to increase the muscle activity rapidly. This exercise technique was found to be the most effective in developing activation, particularly with a frequency of $15 \mathrm{~Hz}$ for multifidus and erector spinae muscles in plank, for rectus abdominis muscle in $\mathrm{V}$ crunch and for abdominal oblique externus muscle in single bridge. ${ }^{[31]}$

However, a Cochrane review on the effectiveness of exercise therapy in non-specific CLBP ${ }^{[32]}$ reported that spinal stabilization exercises do not provide a longer-term advantage compared to other exercise programs and exercise therapy is usually mildly effective in reducing pain and improving function in CLBP. In binary meta-analyses examining specific exercise types, pilates, yoga, and stabilization/motor control exercise programs were found to be more effective in reducing pain and increasing functionality than non-exercise training programs. ${ }^{[26,33]}$ Another review demonstrated that there was low-quality evidence that aerobic, stabilization/motor control exercise training and pilates were optimal for controlling pain, as for improving physical function and reducing disability, and there was low-quality evidence that stabilization/motor control and resistance exercise training were the most effective. ${ }^{[34]}$ 
In McKenzie's mechanical diagnosis and treatment method, the clinician determines the postural positions that should be adopted and should be avoided temporarily, using the information obtained from the postural and functional evaluation of the patient. After making appropriate recommendations on these postural positions, the clinician creates an exercise program accordingly, these exercises are also known as Mckenzie exercises. This program is based on an exercise approach that is preferred in the treatment of discogenic low back pain, where exercises that provide the centralization of the disc are encouraged and peripheralization of the disc is avoided. ${ }^{[35,36]}$

High-intensity interval training (HIIT) exercises, which have been shown to be effective in many chronic diseases in recent years, have also been studied in CLBP. It has been found that the HIIT exercises do not provide an additional benefit for patients with CLBP, when combined with the core strength program and/or resistance exercises. ${ }^{[37]}$

In a systematic review comparing exercise therapy with the combination of exercise and patient training in preventing recurrence of lumbar back pain, both options prevented new episodes and lumbar back pain related absenteeism, but the combination of exercise and patient education was more effective. ${ }^{[38]}$ Since low back pain is a cause of recurrent disability, the correct exercise program and training appropriate for the individual needs and preferences of the patient is also recommended for the post-treatment period..$^{[2,3]}$

\section{PHYSICAL THERAPY OPTIONS}

In the NASS guide, therapeutic ultrasound is reported as ineffective on function in CLBP and controversial in rapid pain control..$^{[7]}$ A Cochrane review published in 2020 reported that the use of ultrasound in the treatment of CLBP was ineffective on pain, but might be effective on function in the short term compared to placebo, although the level of evidence was low. ${ }^{[39]}$ Therefore, the authors concluded that there were insufficient data to support the use of ultrasound in the treatment of CLBP (Table 2). ${ }^{[39]}$

The addition of laser therapy to exercise program has been reported to provide better pain control than these two treatments alone in CLBP. ${ }^{[7]} \mathrm{A}$ recent study investigating the effectiveness of laser therapy in non-specific CLBP reported that both high-intensity

\begin{tabular}{|c|c|}
\hline $\begin{array}{l}\text { TABLE } 2 \\
\text { Non-pharmacological treatment for chronic low back pain }{ }^{[7]}\end{array}$ & \\
\hline & Grade of recommendation \\
\hline $\begin{array}{l}\text { Back school: Provides better improvement in pain and function when compared with general medical } \\
\text { care or a simple handout at 6-12 months follow-up for CLBP }\end{array}$ & A \\
\hline McKenzie method: A valid option for the treatment of chronic low back pain. & $\mathrm{C}$ \\
\hline Yoga: May offer medium term improvements in pain and function compared to usual care & $\mathrm{B}$ \\
\hline $\begin{array}{l}\text { Acupuncture: Addition of it to usual care is recommended for short-term improvement of pain and } \\
\text { function compared to usual care alone }\end{array}$ & A \\
\hline Home-based exercise program: Insufficient evidence to compare with no treatment & I \\
\hline Lumbar stabilization exercises: Insufficient evidence to make a recommendation for or against & I \\
\hline Dry needling: Insufficient evidence to make a recommendation for or against & I \\
\hline $\begin{array}{l}\text { Ultrasound: Insufficient evidence to prove it provides immediate pain relief in patients with chronic } \\
\text { low back pain }\end{array}$ & I \\
\hline $\begin{array}{l}\text { Spinal manipulative therapy: Conflicting evidence on outcomes for CLBP compared to no treatment, } \\
\text { medication or other physical therapy modalities }\end{array}$ & I \\
\hline $\begin{array}{l}\text { McKenzie method: Insufficient evidence to state it has better results when compared to a dynamic } \\
\text { strengthening program or a back school }\end{array}$ & I \\
\hline $\begin{array}{l}\text { Laser acupuncture: Provides no short-term or medium-term benefit over sham treatment for patients } \\
\text { with CLBP }\end{array}$ & A \\
\hline $\begin{array}{l}\text { Traction: Not recommended, not expected to provide clinically significant improvements in pain or } \\
\text { function }\end{array}$ & A \\
\hline Ultrasound: Not recommended, not expected to improve functional outcomes & A \\
\hline
\end{tabular}


laser therapy (HILT) and low-level laser therapy (LLLT) were significantly more effective than placebo in pain control and quality of life and they showed no superiority to each other. ${ }^{[40]}$

Concerning transcutaneous electrical nerve stimulation (TENS), the results are controversial in terms of both function and short-term pain control. ${ }^{[7]}$ Therefore, passive electrical or physical methods such as ultrasound, TENS, traction, interferential current, shortwave diathermy and the use of a corset are usually not recommended (Table 2). ${ }^{[2,3,23]}$ Nevertheless, in a new systematic review, electrotherapy was found to reduce fear-avoidance beliefs with moderate-quality evidence. ${ }^{[25]}$

The guideline prepared by the American College of Physicians (ACP) $)^{[41]}$ endorses superficial heat therapy, stating that this recommendation is based on a Cochrane review ${ }^{[42]}$ showing moderate-quality evidence on short duration of pain control with superficial heat, compared to oral placebo or dressing without warming. ${ }^{[23]}$ In a study from Turkey, physical therapy methods (hot pack, ultrasound and TENS) added to exercise and medical therapy in patients with CLBP were found to have a more positive effect on pain and functional status than exercise and medical treatment alone and this effect continued for up to a year. ${ }^{[43]}$

Transcranial direct stimulation (tDCS) is a treatment approach that exerts its analgesic efficacy by reducing cortical excitability and has been increasingly used in the treatment of pain in recent years. It has been reported that there are a few studies investigating the effectiveness of tDCS in the treatment of CLBP and these studies do not show effectiveness on pain, functional status, and quality of life. ${ }^{[44]}$

\section{PSYCHOSOCIAL STRATEGIES}

There is a strong relationship between the success of treatment in low back pain and psychosocial factors such as the patient's self-efficacy, pain catastrophizing, and kinesiophobia. ${ }^{[36]}$ Psychosocial strategies are used in cases where patient education is insufficient to maintain mobility and to ensure participation in daily activities, including work, which are very important elements of the first step treatment. ${ }^{[2,3]}$

Although psychological therapies such as CBT, mindfulness, and multidisciplinary therapy are not recommended in the treatment of acute low back pain, it is known that psychological factors are effective in the chronicity of pain. In addition, the psychological state of the patient is a strong determinant for the level of disability if/when the chronicity occurs. ${ }^{[23]}$

The CLBP treatment guidelines recommend evaluating psychological treatments (CBT, progressive relaxation, and mindfulness-based stress reduction) for patients with persistent back pain or radicular pain that have not responded to previous treatments. Multidisciplinary rehabilitation programs consisting of controlled exercise therapy, CBT, and simultaneous administration of drugs have been found to be more effective than standard treatments for patients whose functionality are significantly impaired and who do not respond to first-line treatments. ${ }^{[2]}$ However, it should be kept in mind that treatment methods such as manual therapy, exercise, physical therapy, craniosacral therapy, and kinesiotaping also contribute to pain control and reduce pain and fear of movement. ${ }^{[45]}$

\section{COMPLEMENTARY MEDICINE METHODS}

Some guidelines do not recommend passive therapies such as spine manipulation/mobilization, massage, and acupuncture, while some guidelines view them as optional and recommend a trial of appropriate duration for patients who do not respond to first-line treatment. ${ }^{[2]}$

The United States (US) and Denmark guidelines $^{[40,46]}$ recommend passive spine manipulation and massage only in cases where other treatments are ineffective. However, the evidence for both treatments is conflicting. A Cochrane review on this subject reported that massage is not effective and not recommended in CLBP. ${ }^{[23]}$ The English guideline ${ }^{[47]}$ states that spinal manipulation and massage can be only applied with an exercise program.

The muscle energy technique (MET), a manual therapy technique using isometric contraction energy to relax the muscles via reciprocal or autogenic inhibition, is another option for the management of CLBP. The MET is shown to be effective as a stand-alone treatment or in combination with other treatment strategies in CLBP. ${ }^{[48]}$

The evidence for acupuncture is, likewise, conflicting. The US guideline recommends acupuncture, if there is not enough response to other treatments. However, this recommendation is based on low-quality evidence showing that acupuncture is short-term and slightly more effective, compared to sham therapy. ${ }^{[23]}$ In a review on acupressure therapy, 


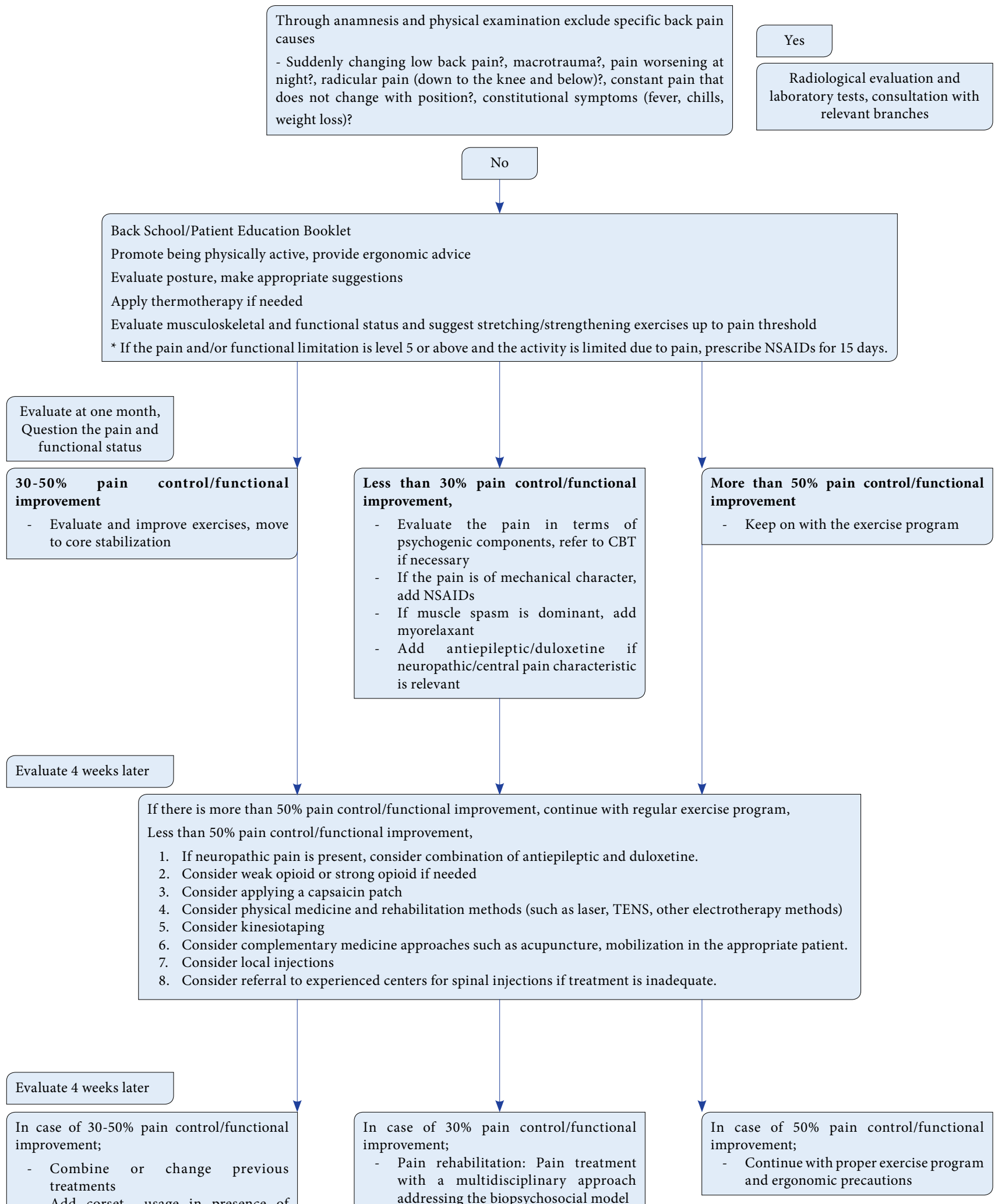


the authors found this method to be effective in both pain and disability in patients with CLBP. ${ }^{[49]}$ In a Cochrane review published in 2020, it was shown that it might not affect pain and functions in the short term, but it might increase functions in the immediate term (right after the treatment). ${ }^{[50]}$ The authors concluded that acupuncture might be chosen according to accessibility, cost, and patient preference in CLBP.

A review showed that Spa therapy was beneficial for CLBP and it achieved this effect by inducing changes in gene expression modulation and proteins involved in functions such as angiogenesis, tissue repair, and acute and chronic inflammatory response. ${ }^{[51]}$

Another complementary medicine method that has attracted increasing attention in recent years is kinesiotaping. In a review, it was not found to be effective when used alone in patients with chronic non-specific low back pain, but when added to the first-line treatments, it is particularly effective in increasing movement. ${ }^{[22]}$ However, in a study conducted in Turkey and in a review specific to low back pain, long-term positive effects were reported on pain and quality of life either alone or when added to regular treatment in acute and CLBP. ${ }^{[3,54]}$

Currently, there are not enough data available on whether diet and weight loss are effective in low back pain. ${ }^{[7]}$

In summary, the common approach in this regard is that complementary medicine approaches can be effective in pain control, these methods can be used, if other treatment options are unsuccessful; however, the patient should not be allowed to abandon the activity. ${ }^{[5]}$

\section{OTHER TREATMENTS}

Another controversial approach in the treatment of CLBP is the use of corsets. The use of a corset in addition to NSAIDs was found to be more effective on pain and functional status in the short term, compared to the use of NSAIDs alone in a study from Turkey. Also, lumbosacral corsets were found to be superior to elastic braces. ${ }^{[56]}$

Technology-supported exercise therapy has been used in recent years, thanks to systems using electromyography feedback (EMG-FB). In a recent systematic review, exercise with this method has been shown to provide improvement in pain, disability, and quality of life in patients with low back pain. However, for most EMG-FB systems, the level of evidence is not yet sufficient to place this method in routine clinical practice, as a limited number of studies have been conducted. ${ }^{[36]}$

Virtual reality is recommended as an alternative to opioids in the treatment of acute and CLBP. Not all the therapeutic mechanisms of virtual reality in CLBP are yet known, but distraction, neuromodulation of body perception and gradual exposure are among the known mechanisms. Virtual reality may show more efficacy in CLBP patients with kinesiophobia and greater effect can be achieved with more intensive use. Further randomized-controlled studies are needed in this area. ${ }^{[57]}$

Another approach in patients with CLBP is generating kinesthetic and visual motor imagery, mental motor imagery approach. It has been reported that mental motor imagery added to therapeutic exercises contributes to pain control and reduction of disability. ${ }^{[58]}$

Regenerative treatments are among the areas investigated in the treatment of CLBP among intradiscal treatments. Stem cell therapies, platelet-rich plasma injections are applied to the facet joints and disc, but there is not enough data on their efficacy and safety, yet. ${ }^{[59]}$

In the light of these data, we suggest an algorithm about conservative treatment of low back pain in Figure 1.

In conclusion, CLBP is the most common cause of disability in the world and although it has been the subject of many studies, this area needs to be examined more. As the peripheral and central pathologies accompanying the picture at different rates, staying still and prolonging life with the development of societies contributing to the problem and its biopsychosocial characteristics, CLBP should be investigated more in terms of both diagnosis and treatment.

\section{Declaration of conflicting interests}

The authors declared no conflicts of interest with respect to the authorship and/or publication of this article.

Funding

The authors received no financial support for the research and/or authorship of this article.

\section{REFERENCES}

1. Hartvigsen J, Hancock MJ, Kongsted A, Louw Q, Ferreira $\mathrm{ML}$, Genevay S, et al. What low back pain is and why we need to pay attention. Lancet 2018;391:2356-67. 
2. Foster NE, Anema JR, Cherkin D, Chou R, Cohen SP, Gross DP, et al. Prevention and treatment of low back pain: evidence, challenges, and promising directions. Lancet 2018;391:2368-83.

3. Oliveira CB, Maher CG, Pinto RZ, Traeger AC, Lin CC, Chenot JF, et al. Clinical practice guidelines for the management of non-specific low back pain in primary care: an updated overview. Eur Spine J 2018;27:2791-803.

4. Fornari M, Robertson SC, Pereira P, Zileli M, Anania CD, Ferreira A, et al. Conservative treatment and percutaneous pain relief techniques in patients with lumbar spinal stenosis: WFNS spine committee recommendations. World Neurosurg X 2020;7:100079.

5. Kreiner DS, Hwang SW, Easa JE, Resnick DK, Baisden JL, Bess S, et al. An evidence-based clinical guideline for the diagnosis and treatment of lumbar disc herniation with radiculopathy. Spine J 2014;14:180-91.

6. Parr A, Askin G. Non-radicular low back pain: Assessment and evidence-based treatment. Aust J Gen Pract 2020;49:724-7.

7. Kreiner DS, Matz P, Bono CM, Cho CH, Easa JE, Ghiselli $\mathrm{G}$, et al. Guideline summary review: an evidence-based clinical guideline for the diagnosis and treatment of low back pain. Spine J 2020;20:998-1024.

8. Suman A, Armijo-Olivo S, Deshpande S, Marietta-Vasquez J, Dennett L, Miciak M, et al. A systematic review of the effectiveness of mass media campaigns for the management of low back pain. Disabil Rehabil 2020:1-29.

9. Saragiotto BT, Machado GC, Ferreira ML, Pinheiro MB, Abdel Shaheed C, Maher CG. Paracetamol for low back pain. Cochrane Database Syst Rev 2016;2016:CD012230.

10. Chou R, Deyo R, Friedly J, Skelly A, Weimer M, Fu R, et al. Systemic pharmacologic therapies for low back pain: A systematic review for an American College of Physicians Clinical Practice Guideline. Ann Intern Med 2017;166:480-92.

11. Bhatia A, Engle A, Cohen SP. Current and future pharmacological agents for the treatment of back pain. Expert Opin Pharmacother 2020;21:857-61.

12. Rasmussen-Barr E, Held U, Grooten WJ, Roelofs PD, Koes BW, van Tulder MW, et al. Non-steroidal antiinflammatory drugs for sciatica. Cochrane Database Syst Rev 2016;10:CD012382.

13. Abdel Shaheed C, Maher CG, Williams KA, McLachlan AJ. Efficacy and tolerability of muscle relaxants for low back pain: Systematic review and meta-analysis. Eur J Pain 2017;21:228-37.

14. Shanthanna H, Gilron I, Rajarathinam M, AlAmri R, Kamath S, Thabane L, et al. Benefits and safety of gabapentinoids in chronic low back pain: A systematic review and meta-analysis of randomized controlled trials. PLoS Med 2017;14:e1002369.

15. Mathieson S, Maher CG, McLachlan AJ, Latimer J, Koes BW, Hancock MJ, et al. Trial of pregabalin for acute and chronic sciatica. N Engl J Med 2017;376:1111-20.

16. Urquhart DM, Hoving JL, Assendelft WW, Roland $M$, van Tulder MW. Antidepressants for nonspecific low back pain. Cochrane Database Syst Rev 2008;2008:CD001703.
17. Weng C, Xu J, Wang Q, Lu W, Liu Z. Efficacy and safety of duloxetine in osteoarthritis or chronic low back pain: a systematic review and meta-analysis. Osteoarthritis Cartilage 2020;28:721-34.

18. Santana JA, Klass S, Felix ER. The efficacy, effectiveness and safety of $5 \%$ transdermal lidocaine patch for chronic low back pain: A narrative review. PM R 2020;12:1260-7.

19. Peck J, Urits I, Peoples S, Foster L, Malla A, Berger AA, et al. A Comprehensive review of over the counter treatment for chronic low back pain. Pain Ther 2020 . [Online ahead of print]

20. Ge J, Cheng X, Yan Q, Wu C, Wang Y, Yu H, et al. Calcitonin inhibits intervertebral disc degeneration by regulating protein kinase C. J Cell Mol Med 2020;24:8650-61.

21. Bråten LCH, Grøvle L, Espeland A, Pripp AH, Grotle M, Helllum $\mathrm{C}$, et al. Clinical effect modifiers of antibiotic treatment in patients with chronic low back pain and Modic changes - secondary analyses of a randomised, placebocontrolled trial (the AIM study). BMC Musculoskelet Disord 2020;21:458.

22. Chen F, Jiang G, Liu H, Li Z, Pei Y, Wang H, et al. Melatonin alleviates intervertebral disc degeneration by disrupting the IL-1 $\beta / N F-\kappa B-N L R P 3$ inflammasome positive feedback loop. Bone Res 2020;8:10.

23. O'Keeffe M. Non-pharmacological treatment of low back pain in primary care. Drug Ther Bull 2019;57:104-8.

24. Corp N, Mansell G, Stynes S, Wynne-Jones G, Morsø L, Hill JC, et al. Evidence-based treatment recommendations for neck and low back pain across Europe: A systematic review of guidelines. Eur J Pain 2020. [Online ahead of print]

25. Martinez-Calderon J, Flores-Cortes M, Morales-Asencio JM, Luque-Suarez A. Conservative interventions reduce fear in individuals with chronic low back pain: a systematic review. Arch Phys Med Rehabil 2020;101:329-58.

26. Owen PJ, Miller CT, Mundell NL, Verswijveren SJJM, Tagliaferri SD, Brisby $\mathrm{H}$, et al. Which specific modes of exercise training are most effective for treating low back pain? Network meta-analysis. Br J Sports Med 2020;54:1279-87.

27. Ahmadi H, Adib H, Selk-Ghaffari M, Shafizad M, Moradi $S$, Madani Z, et al. Comparison of the effects of the Feldenkrais method versus core stability exercise in the management of chronic low back pain: a randomised control trial. Clin Rehabil 2020;34:1449-57.

28. Dillingham T, Kenia J, Popescu A, Plastaras C, Becker $S$, Shofer F. Pain outcomes with an elliptical regimen (POWER) study: Identifying the proper dosage of exercise for therapeutic effect in persons with chronic back pain. J Phys Med Rehabil 2020;2:23-8.

29. Mueller J, Niederer D. Dose-response-relationship of stabilisation exercises in patients with chronic non-specific low back pain: a systematic review with meta-regression. Sci Rep 2020;10:16921.

30. Moghadam N, Ghaffari MS, Noormohammadpour P, Rostami M, Zarei M, Moosavi M, et al. Comparison of the recruitment of transverse abdominis through drawing-in and bracing in different core stability training positions. J Exerc Rehabil 2019;15:819-25. 
31. Dong Y, Wang H, Zhu Y, Chen B, Zheng Y, Liu X, et al. Effects of whole body vibration exercise on lumbarabdominal muscles activation for patients with chronic low back pain. BMC Sports Sci Med Rehabil 2020;12:78.

32. Hayden JA, van Tulder MW, Malmivaara A, Koes BW. Exercise therapy for treatment of non-specific low back pain. Cochrane Database Syst Rev 2005;(3):CD000335.

33. Stankovic A, Lazovic M, Kocic M, Dimitrijevic L, Stankovic I, Zlatanovic D, et al. Lumbar stabilization exercises in addition to strengthening and stretching exercises reduce pain and increase function in patients with chronic low back pain: randomized clinical open-label study. Turk J Phys Med Rehab 2012;58:177-83.

34. Owen PJ, Miller CT, Mundell NL, Verswijveren SJJM, Tagliaferri SD, Brisby H, et al. Infographic. What kinds of exercise are best for chronic low back pain? Br J Sports Med 2020;54:1231-2.

35. Namnaqani FI, Mashabi AS, Yaseen KM, Alshehri MA. The effectiveness of McKenzie method compared to manual therapy for treating chronic low back pain: a systematic review. J Musculoskelet Neuronal Interact 2019;19:492-9.

36. Shipton EA. Physical therapy approaches in the treatment of low back pain. Pain Ther 2018;7:127-37.

37. Verbrugghe J, Agten A, Stevens S, Hansen D, Demoulin C, Eijnde BO, et al. High intensity training to treat chronic nonspecific low back pain: Effectiveness of various exercise modes. J Clin Med 2020;9:2401.

38. Huang R, Ning J, Chuter VH, Taylor JB, Christophe D, Meng Z, et al. Exercise alone and exercise combined with education both prevent episodes of low back pain and related absenteeism: systematic review and network metaanalysis of randomised controlled trials (RCTs) aimed at preventing back pain. Br J Sports Med 2020;54:766-70.

39. Ebadi S, Henschke N, Forogh B, Nakhostin Ansari N, van Tulder MW, Babaei-Ghazani A, et al. Therapeutic ultrasound for chronic low back pain. Cochrane Database Syst Rev 2020;7:CD009169.

40. Abdelbasset WK, Nambi G, Alsubaie SF, Abodonya AM, Saleh AK, Ataalla NN, et al. A randomized comparative study between high-intensity and low-level laser therapy in the treatment of chronic nonspecific low back pain. Evid Based Complement Alternat Med 2020;2020:1350281.

41. Qaseem A, Wilt TJ, McLean RM, Forciea MA, Clinical guidelines committee of the american college of physicians. Noninvasive treatments for acute, subacute, and chronic low back pain: a clinical practice guideline from the American College of Physicians. Ann Intern Med 2017;166:514-30.

42. French SD, Cameron M, Walker BF, Reggars JW, Esterman AJ. A Cochrane review of superficial heat or cold for low back pain. Spine (Phila Pa 1976) 2006;31:998-1006.

43. Şahin N, Karahan AY, Albayrak İ. Effectiveness of physical therapy and exercise on pain and functional status in patients with chronic low back pain: a randomizedcontrolled trial. Turk J Phys Med Rehabil 2018;64:52-8.

44. Alwardat M, Pisani A, Etoom M, Carpenedo R, Chinè E, Dauri $\mathrm{M}$, et al. Is transcranial direct current stimulation (tDCS) effective for chronic low back pain? A systematic review and meta-analysis. J Neural Transm (Vienna) 2020;127:1257-70.

45. Tagliaferri SD, Miller CT, Owen PJ, Mitchell UH, Brisby H, Fitzgibbon B , et al. Domains of chronic low back pain and assessing treatment effectiveness: A clinical perspective. Pain Pract 2020;20:211-25.

46. Stochkendahl MJ, Kjaer P, Hartvigsen J, Kongsted A, Aaboe J, Andersen M, et al. National Clinical Guidelines for nonsurgical treatment of patients with recent onset low back pain or lumbar radiculopathy. Eur Spine J 2018;27:60-75.

47. National Institute for Health and Care Excellence. Low back pain and sciatica in over 16s: assessment and management (NG59) [online]. 2016. Available at: https://www. nice. org. uk/guidance/ng59 [Accessed: March 20, 2019]

48. Ahmed UA, Nadasan T, Van Oosterwijck J, Maharaj SS. The effect of muscles energy technique in the management of chronic mechanical low back pain: A scoping review. J Back Musculoskelet Rehabil 2020. [Online ahead of print]

49. Godley E, Smith MA. Efficacy of acupressure for chronic low back pain: A systematic review. Complement Ther Clin Pract 2020;39:101146.

50. Mu J, Furlan AD, Lam WY, Hsu MY, Ning Z, Lao L. Acupuncture for chronic nonspecific low back pain. Cochrane Database Syst Rev 2020;12:CD013814.

51. Angioni MM, Denotti A, Pinna S, Sanna C, Montisci F, Dessole G, et al. Spa therapy induces clinical improvement and protein changes in patients with chronic back pain. Reumatismo 2019;71:119-31.

52. Pergolizzi JV Jr, LeQuang JA. Rehabilitation for low back pain: A narrative review for managing pain and improving function in acute and chronic conditions. Pain Ther 2020;9:83-96.

53. Sheng Y, Duan Z, Qu Q, Chen W, Yu B. Kinesio taping in treatment of chronic non-specific low back pain: a systematic review and meta-analysis. J Rehabil Med 2019;51:734-40.

54. Uzunkulaoğlu A, Güneş Aytekin M, Ay S, Ergin S. The effectiveness of Kinesio taping on pain and clinical features in chronic non-specific low back pain: A randomized controlled clinical trial. Turk J Phys Med Rehabil 2018;64:126-32.

55. Licciardone JC, Pandya V. Use of complementary health approaches for chronic low-back pain: a pain research registry-based study. J Altern Complement Med 2020;26:369-75.

56. Ay Uslusoy G, Savaş S. Kronik bel ağrılı hastalarda ekstansiyon kontrollü ve elastik lomber korselerin kısa dönemdeki etkinliği ve korse uyumuna etki eden faktörler: Randomize kontrollü klinik çalışma. Türk Fiz Tıp Rehab Derg 2013;59:182-8.

57. Tack C. Virtual reality and chronic low back pain. Disabil Rehabil Assist Technol 2019:1-9.

58. Grande-Alonso M, Garrigos-Pedron M, Cuenca-Martinez F, Vidal-Quevedo C, Prieto-Aldana M, La Touche R, et al. Influence of the generation of motor mental images on physiotherapy treatment in patients with chronic low back pain. Pain Physician 2020;23:E399-E408.

59. Urits I, Viswanath O, Galasso AC, Sottosani ER, Mahan KM, Aiudi CM, et al. Platelet-rich plasma for the treatment of low back pain: A comprehensive review. Curr Pain Headache Rep 2019;23:52. 